\title{
TELMISARTAN IN THE TREATMENT OF HYPERTENSION IN PATIENTS WITH CHRONIC RENAL INSUFFICIENCY
}

\author{
Otilie Weinbergováa ${ }^{a^{*}}$, Rudolf Metelka ${ }^{b}$, Jiří Vymětal ${ }^{b}$, Karel Konečnýb, Zdena Kosatíkováa \\ a Faculty of Medicine, Palacky University, Olomouc, Czech Republic \\ ${ }^{b}$ 3rd Clinic of Internal Medicine, Teaching Hospital, Olomouc
}

Received: March 15, 2004; Accepted: May 19, 2004

Key words: Renal insufficiency/Proteinuria/Antihypertensive therapy/Angiotensin II receptor blockers/AT1 blockers/Heart rate variability

The primary aim of this study was evaluation of the efficacy of telmisartan (angiotensin II receptor blocker- $\mathrm{AT}_{1}$ blocker) on blood pressure in 10 patients with renal impairment in moderate or advanced stages of renal insufficiency and not dependent on haemodialysis. Its effect on proteinuria, renal function (represented by serum urea, creatinine, glomerular filtration), evaluation of overall therapy compliance in comparison with a previously prescribed angiotensin converting enzyme inhibitors (ACEI) were secondary aims. Considering the presence of left ventricle hypertrophy in all patients as a marker of hypertensive cardiopathy, the effect of telmisartan therapy on non-invasive cardiovascular parameters (ECG, echocardiography, and assessment of heart rate variability-HRV) was also evaluated.

The study group involved 10 hypertensive patients ( 6 women, 4 men) with diabetic and non-diabetic renal impairment, proteinuria above $1 \mathrm{~g} / 24$ hours, hypertensive cardiopathy and intolerance of ACEI (cough). Telmisartan was added to their long-term antihypertensive combination therapy in a dose of $40 \mathrm{mg}$ for the first 14 days, after which the dose increased to the maximal of $80 \mathrm{mg}$.

The average initial daytime systolic blood pressure (SBP) was $149 \pm 19.7 \mathrm{~mm} \mathrm{Hg}$, average night-time SBP 145 $\pm 23.0 \mathrm{~mm} \mathrm{Hg}$, average initial daytime diastolic BP (DBP) $90.6 \pm 2.5 \mathrm{~mm} \mathrm{Hg}$, night-time DBP $88.9 \pm 13.5 \mathrm{~mm} \mathrm{Hg}$. Average initial serum creatinine was $207.2 \pm 48.5 \mu \mathrm{mol} / 1$, urea $15.1 \pm 4.4 \mathrm{mmol} / 1$, GF $0.5 \pm 0.1 \mathrm{ml} / \mathrm{s}$. Echocardiography revealed left ventricular (LV) hypertrophy with well preserved systolic and moderately impaired diastolic LV function. Also the HRV assessment revealed impaired neurovegetative (e.g. sympathovagal) balance. After 1 year of combination therapy with telmisartan, there was a clearly significant reduction in both SBP and DBP in both day and night-time (SBP daytime 149.6 vs.116.6 mm Hg, night-time 145.8 vs. $129.5 \mathrm{~mm} \mathrm{Hg}$; DBP daytime 90.6 vs. $83.5 \mathrm{~mm} \mathrm{Hg}$, night-time 88.9 vs. $79,3 \mathrm{~mm} \mathrm{Hg})$ and proteinuria $(2.37$ vs. $1.27 \mathrm{~g} / 24$ hour, $\mathrm{p}<0.05)$. There were no significant changes in serum creatinine, urea values, and LV functions. On the other hand, further progression of the sympathovagal balance impairment was noted (continuing reduction of HRV in 9 from 10 patients), which can be described as the priority finding. The total compliance of telmisartan therapy was very good and without adverse clinical side effects.

In conclusion - telmisartan reduces blood pressure and proteinuria safely and effectively in patients with various types of nephropathy in moderate or advanced stages of renal insufficiency.

\section{INTRODUCTION}

Inhibition of renin-angiotensin-aldosterone system (RAA) results in reduced progression and diminished clinical symptoms in many cardiovascular diseases. The treatment of these drugs has been proven multicentric trials, the results of which have been published over the past five years ${ }^{1-3}$. Experimental and clinical trials focused at renal parameters have also been performed ${ }^{4-7}$. The evidence for the positive effects of angiotensin converting enzyme (ACEI) and angiotensin II receptor blockers (ARBs) exceed their effect on the blood pressure resulted in the opinion that the RAA system plays an important role in the pathophysiology and progression of renal diseases. The octapeptide angiotensin II (Ang-II) is the main effector of RAA system with a lot of renal consequences ranging from the haemodynamic control to the influence on the morphology of renal cells, tubular functions, immunomodulative and anti-inflammatory effects, as far as the interactions with other humoral or endocrine systems. The majority of known Ang-II effects are mediated by angiotensin receptors-type 1 (AT1). It was found that local renal Ang-II enhances the glomerular efferent arteriolar tension and thus the intraglomerular pressure, glomerular permeability and proteinuria. ACEI are potent blockers of Ang-II production. A positive influence of ACEI on the further progression of glomerulopathy and renal insufficiency has been demonstrated in a number of experimental and clinic trials, particularly in patients with diabetic nephropathy ${ }^{9}{ }^{10}$. ACEI slowed the rate of progression of renal insufficiency in these patients and reduced albuminuria. Two studies (AIPRI, REIN) also showed marked reduction in the progression of renal insufficiency in non-diabetic nephropathy ${ }^{8,11}$. As in cardi- 
ology, the more marked nephroprotective effect of ARBs therapy was expected in nephrology as well, especially for more complex Ang-II blockade. Trials with losartan, valsartan and candesartan showed antihypertensive effects comparable to other trials with ACEI and practically the same nephroprotective effect ${ }^{12-14}$. Thus the contemporary experience with the renal effects of ARBs in chronic nephropathy patients is much lower than that with ACEI.

In connection with these well-known facts we were interested in the effect of Ang-II receptor blocker telmisar$\tan$ (Micardis) in patients with renal insufficiency without dialysis treatment, with moderate proteinuria, hypertension and hypertensive cardiopathy. We selected the patient group with ACEI intolerance, mostly manifest as irritable cough. The primary aim of our study was evaluation of the efficacy of telmisartan antihypertensive treatment of patients with renal disease in moderate or advanced stages of renal insufficiency. The secondary aims were the effects on proteinuria, serum creatinine and potassium as well as the evaluation of the influence on cardiovascular system, assessment of patient compliance of telmisartan compared to previously prescribed ACEI.

\section{MATERIALS AND METHODS}

The study included 10 patients with diabetic and non-diabetic renal impairment, followed long-term in our specialised facility. Four had diabetic nephropathy, five had chronic glomerulonephritis and one had vascular nephrosclerosis and interstitial nephritis. Their diagnosis was based on clinical and laboratory findings and in $50 \%$ on renal biopsy. Proteinuria above $1 \mathrm{~g} / 24 \mathrm{~h}$, hypertension and the intolerance of ACEI were common denominators in all patients. Exclusion criteria were: renovascular or malignant hypertension, history of myocardial infarction or cerebral events, claudications, chronic heart failure, chronic liver or lung diseases, systemic diseases, steroid or immunosuppressive treatment, alcohol abuse.

At the beginning of the study, each patient underwent physical examination, blood pressure (BP) and heart rate (HR) measurement, laboratory testing (serum $\mathrm{Na}, \mathrm{K}, \mathrm{Ca}$, P, urea, creatinine, uric acid, ALT, AST, ALP, GMT, total cholesterol, triglycerides, glucose, total proteins, albumin), total blood count. Glomerular filtration was assessed by creatinine clearance $(C L R=$ urine creatinine $\times 24$ hour diuresis / serum creatinine and result was converted to patient's body surface, $\mathrm{ml} / \mathrm{s} / \mathrm{m}^{2}$ ); proteinuria was calculated as urine protein concentration after the 24-hour samples $(\mathrm{g} /$ day). All patients underwent non-invasive ambulatory 24-hour BP monitoring (ABPM) by arm-cuff method with pressure monitor Cardiette BP One (Elletronica Trentina S.p.A, Italy), ECG, maximum or symptom-limited bicycle ergometry. A transthoracic echocardiography (Hewlett Packard ImagePoint) was performed by the same physician to assess the global systolic function (left ventricle ejection fraction, LVEF), LV enddiastolic diameter, semiquantitative $\mathrm{LV}$ diastolic function (E, A wave, type of dysfunction) and valve function.
Heart rate variability (HRV) was used for assessment of the sympathovagal balance and neuroendocrine activation, which are influenced both by impaired metabolic parameters of renal insufficiency and by RAA system (Fig. 1). The measurement was performed under standardised conditions with telemetric computer-aided system VariaPulse TF4 before and after 1-year telmisartan therapy. The used method of HRV measurement is based on short-term spectral analysis of HRV during modified orthoclinostatic test (supine-standing-supine), which is a functional test with vagal load ${ }^{16}$ (Fig. 1). The results were processed by the software program VariaCa 2.0 enabling to assess so-called the "functional age of the autonomic nervous system" (ANS) in comparison with an age-matched healthy control population. Using a scale from -5 to +5 , the complex parameters of ANS were evaluated, i.e. parameter "vagal activity", parameter "sympathovagal balance" and parameter "total score" 17 . Depression of total score means a sympathetic, i.e. neuroendocrine activation.

Laboratory testing was performed monthly over 6 months to observe any adverse effects of the treatment, the functional renal testing, ABPM, echocardiography and HRV measurement after 3, 6 and 12 months. Ergometry was repeated after 6 months.

The pharmacotherapy was not changed during the study. Telmisartan was added in the dose of $40 \mathrm{mg} /$ day at the beginning of the study. After 14 days the dose was increased to $80 \mathrm{mg} /$ day. Statistical analyses using ANOVA compared the results before and after 12 months of therapy with telmisartan.

\section{RESULTS AND DISCUSSION}

The average initial daytime systolic blood pressure (s-BPd, from $6 \mathrm{AM}$ to $10 \mathrm{PM}$ ) was $149.6 \pm 19.7 \mathrm{~mm} \mathrm{Hg}$, average night-time s-BP (s-BPn, from 10PM to 6AM) was $145.8 \pm 23 \mathrm{~mm} \mathrm{Hg}$, average diastolic daytime BP (d-BPd) was $90.6 \pm 2.6 \mathrm{~mm} \mathrm{Hg}$, night-time d-BP (d-BPn) was 88.9 $\pm 13.6 \mathrm{~mm} \mathrm{Hg}$. After 1 year of treatment with telmisartan, average s-BPd was $116.6 \pm 37.7 \mathrm{~mm} \mathrm{Hg}$, s-BPn was 129.5 $\pm 8.8 \mathrm{~mm} \mathrm{Hg}$, d-BPd $83.5 \pm 7,3 \mathrm{~mm} \mathrm{Hg}$, d-BPn was $79.3 \pm$ $5.7 \mathrm{~mm} \mathrm{Hg}$ (Fig. 2). A significant reduction ( $\mathrm{p}<0.05$ ) of $\mathrm{BP}$ was reached, meeting guideline values for treatment of hypertension with proteinuria and renal impairment. During 1-year laboratory testing no significant shift in results of serum potassium was registered. 24 hour diuresis and creatinine clearance (from $0.55 \mathrm{ml} / \mathrm{sec}$ before to $0.68 \mathrm{ml}$ / sec after treatment) increased slightly together with increased serum creatinine (from 207.2 to $224 \mu \mathrm{mol} / \mathrm{l}$ ), urea (from 15.1 to $17.6 \mathrm{mmol} / \mathrm{l}$ ) and uric acid (from 354 to $403 \mu \mathrm{mol} / \mathrm{l})$. The differences were not significant. There was a significant reduction of proteinuria (from 2.37 to $1.27 \mathrm{~g} / 24$ hour, $\mathrm{p}<0.05$ ) (Fig. 3). The other evaluated biochemical parameters did not change (Tab. 1). Echocardiography revealed no significant depression of systolic function in any patient before or during telmisartan treatment. LVEF before treatment varied around 45-54\% 


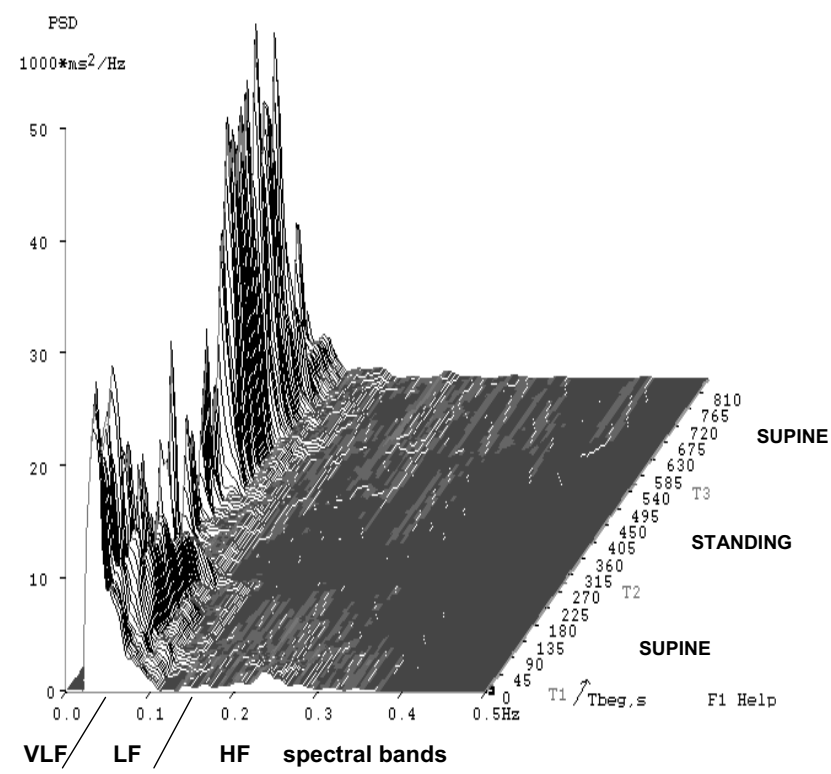

Fig. 1. Short-term spectral analysis of heart rate variability Patient with depressed heart rate variability (high value of the spectral PowerVLF, reduced PowerLF and absent PowerHF). No vagal responsiveness after orthostatic load.

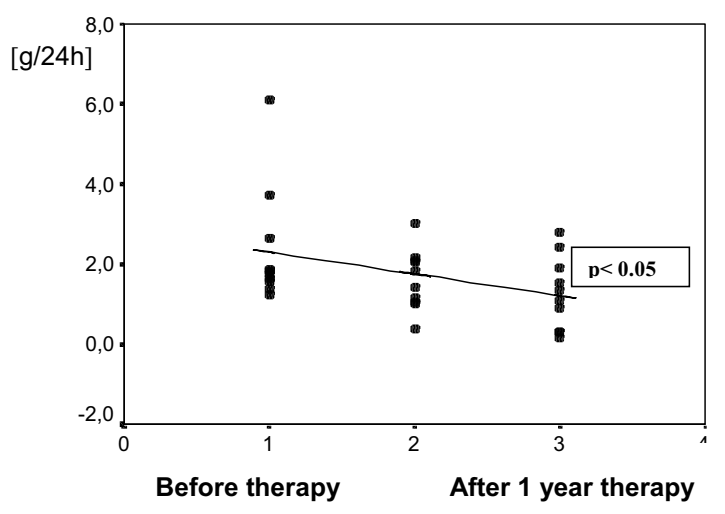

Fig. 3. Proteinuria with telmisartan therapy

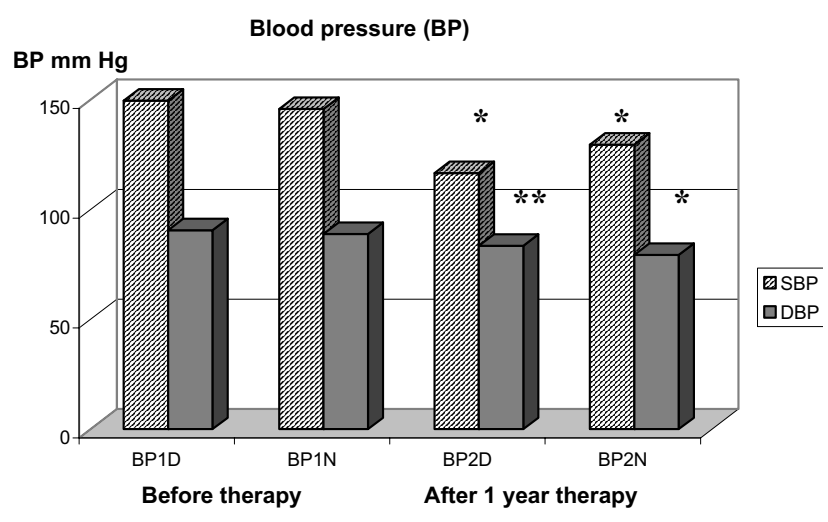

Fig. 2. $B P 1 D(N)$ - blood pressure daytime (night-time) before therapy, BP2D $(\mathrm{N})$ - blood pressure daytime (night-time) after 1 year therapy, SBP - systolic BP, DBP - diastolic BP, * p $<0.05, * * p<0.01$

TS

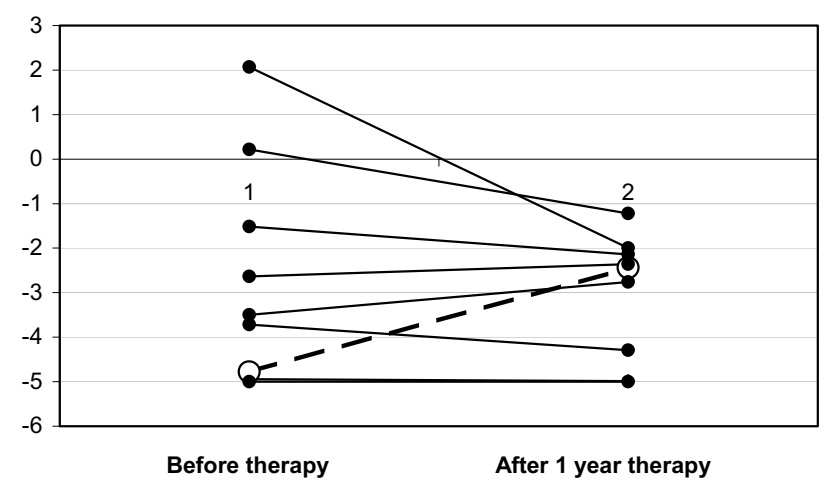

Fig. 4. Heart rate variability - Total score (TS)

Table 1. Laboratory findings.

\begin{tabular}{|l|c|c|c|}
\hline & $\begin{array}{c}\text { Before therapy } \\
(\mathrm{n}=10)\end{array}$ & After 1 year th. $(\mathrm{n}=10)$ & Significance \\
\hline Serum creatinine $[\mu \mathrm{mol} / \mathrm{l}]$ & $207.2 \pm 48.5$ & $224.9 \pm 59.4$ & n. $\mathrm{s}$. \\
\hline Serum urea $[\mathrm{mmol} / \mathrm{l}]$ & $15.1 \pm 4.4$ & $17.28 \pm 6.08$ & n. $s$. \\
\hline Serum uric acid $[\mu \mathrm{mol} / \mathrm{l}]$ & $354.8 \pm 33.6$ & $403.6 \pm 103.5$ & n. $s$. \\
\hline Serum kalium $[\mathrm{mmol} / \mathrm{l}]$ & $4.7 \pm 0.3$ & $5.0 \pm 0.6$ & n. $s$. \\
\hline Clearance $[\mathrm{ml} / \mathrm{s}]$ & $0.5 \pm 0.1$ & $0.6 \pm 0.2$ & n. $s$. \\
\hline Proteinuria $[\mathrm{g} / 24 \mathrm{~h}]$ & $2.4 \pm 1.5$ & $1.3 \pm 0.9$ & $\mathrm{p}<0.05$ \\
\hline
\end{tabular}


(average $\mathrm{LV} \mathrm{EF}=50.4 \pm 2.9 \%$ ), after treatment $40-55 \%$ (average $\mathrm{LVEF}=48.6 \pm 4.5 \%, \mathrm{p}<0.05$ ). All patients had diastolic dysfunction, mostly moderate impairment of LV relaxation continuing throughout the study. There was no serious valve dysfunction. The LV cavity diameter did not change. After 6 months, the ergometric testing revealed a moderate worsening of workload capacity.

In contrast with the optimisation of BP the assessment of HRV revealed neither improvement, nor further progression of the impaired sympathovagal balance, particularly as measured by absolute depression of vagal activity. Only one patient with interstitial nephritis and nephrosclerosis revealed a marked improvement of HRV parameters (Fig. 4).

Telmisartan was tested for treatment in patients with hypertension, proteinuria and moderate or advanced renal insufficiency. Among the sartans, it has the longest biological half-time (over 24 hours). This enables to prescribe it in a single daily dose with well-controlled BP over 24 hours. Its gastrointestinal absorption is rapid, biotransformation occurs in liver and small intestine. It is then eliminated by faeces in $98 \%$. There is only $2 \%$ renal elimination. Therefore the telmisartan dosage does not have to be adjusted to the degree of renal insufficiency. The liver metabolism is not mediated by cytochrome P-450, so the risk of drug interaction is minimised, a factor highly desirable in patients with renal insufficiency and necessary polypragmasia.

In harmony with the literature data ${ }^{19}$, a significant hypotensive (antihypertensive) effect of telmisartan was found. Practically all patients reached the optimal BP, in addition with very good patient compliance. There were no adverse effects in any patient, causing therapy withdrawal. Over 1 year of therapy, proteinuria significantly decreased $(\mathrm{p}<0.05)$ independent of the aetiology of the nephropathy. There was no registered significant elevation of serum potassium, causing the interruption of the treatment, changes in liver markers, concentration of other minerals ( $\mathrm{Na}, \mathrm{Ca}, \mathrm{P}, \mathrm{Cl})$, total proteins or albumin. The concentration of urea, creatinine and uric acid increased non-significantly, together with a non-significant elevation of glomerular filtration measured by creatinine clearance. The explanation of this tendency was based on the fact that primary and secondary renal diseases are usually of a progressive character. It is evident particularly both in chronic non-inflammatory and inflammatory nephropathies with proteinuria over $1 \mathrm{~g} / 24$ hour. With slow glomerular filtration a decrease $5-10 \mathrm{ml} / \mathrm{min} /$ year $(0.08-0.16 \mathrm{ml} / \mathrm{sec} /$ year $)$, patients with initially normal glomerular filtration reach the end stage of renal disease requiring dialysis in 10-20 years ${ }^{19}$. The rate of progression of renal disease is individual with various inflammatory factors involvement, insufficient compensation of metabolic parameters related to patient compliance, motivation and self-discipline. There are also secondary factors, common for all nephropathies, particularly elevation of systemic BP and intraglomerular pressure. In contrast to the simplicity of measuring systemic BP, the assessment of intraglomerular pressure is clinically difficult and it is an indirect estimate only. It is based on measurement of renal blood flow and glomerular filtration. The nephroprotective effects of ACEi and ABRs consist in positive influence on these hemodynamic parameters - they reduce systemic BP, cause selective glomerular efferent arteriolar dilation and thus they decrease the intraglomerular pressure more than other antihypertensive agents. The mechanism of nephroprotective effects of ACEI and ABRs is obviously complex, including also non-hemodynamic factors as restriction of glomerular hypertrophy, positive influences on glomerular permeability to proteins, reduced renal interstitial infiltration macrophages and formation of the growth factors. Due to ACEI or ABRs activity there is diminished progression of interstitial fibrosis. If we consider the result of our work in this context, it can be assumed that the described positive effects of telmisartan are exerted in preserved and reactivity capable glomerules, while it could not be in the non-functional ones. So there occurred an inter-year elevation of serum creatinine and urea, even though only a moderate and non-significant one. This is in agreement with large randomised trials (Collaborative Study Group, RENAAL, IDNT), that found a marked reduction of the progression of renal insufficiency in a defined part of patients with initial creatinine between 120 and $265 \mu \mathrm{mol} / \mathrm{l}$, while in others this parameter was impaired ${ }^{12-14}$. During a year treatment, none of 10 patients manifested cardiac deterioration nor required hospitalisation for acceleration of angina pectoris or heart failure. The subjectively evaluated quality of life was also much improved. There were no objective tools to assess the quality of life parameters. However, it can be derived from the fact that patients keep asking telmisartan to be prescribed in spite of their obligation to partially cover its costs themselves. After 1-year treatment, the parameters of ANS revealed further worsening of the impaired sympathovagal balance. A metabolic explanation was improbable. Nevertheless research evidence in this topic is very scarce. In addition, the published studies evaluate ANS only in dialysed patients. Akselrod ${ }^{20}$, Bonaduce ${ }^{21}$, Taylor ${ }^{22}$ found positive effects of ACEi on ANS, i.e. on HRV parameters. So far, a similar effect has not been proved in sartans (ABRs). Heusser $^{21}$ described further HRV reduction analogous to that registered in the present study. In agreement with this author, the explanation may be found in central effect of accumulated Ang-II, as a common side effect of ABRs therapy in contrary to ACEI one. From the point of ANS the potential positive effect can be expected from the combination therapy with ABRs and ACEI.

\section{CONCLUSION}

Telmisartan, like other previously reported sartans, effectively decreases the blood pressure and proteinuria in patients with moderate and advanced renal insufficiency regardless to its cause. It is well tolerated, it does nor affect other biochemical parameters. During a one- 
year study, no impairment of left ventricle functions was observed. However, a year follow-up is too short to assess an eventual improvement. On the other hand a further worsening of sympathovagal balance was registered, so far without clinical consequences. Further studies should deal with this topic for its more detailed elucidation.

\section{REFERENCES}

1. Yusuf S, Sleight P, Pogue J, Bosch J, Davies R, Dagenais G. (2000) Effects of an angiotensin-converting enzyme-inhibitor, ramipril, on cardiovascular events in high-risk patients. The Heart Outcomes Prevention Study Investigators. N Engl J Med 342, 145-153.

2. Dahlof B, Devereux RB, Kjeldsen SE, Julius S, Beevers G, de Faire U, Fyhrquist F, Ibsen H, Kristiansson K, Lederballe-Pedersen O, Lindholm LH, Nieminen MS, Omvik P, Oparil S, Wedel H. (2002) Cardiovascular morbidity and mortality in the Losartan Intervention For Endpoint reduction in hypertension study (LIFE) a randomised trial against atenolol. Lancet 359, 995-1003.

3. McKelvie RS, Yusuf S, Pericak D, Avezum A, Burns RJ, Probstfield J, Tsuyuki RT, White M, Rouleau J, Latini R, Maggioni A, Young J, Pogue J. (1999) Comparison of candesartan, enalapril, and their combination in congestive heart failure - Randomised evaluation of strategies for left ventricular dysfunction (RESOLVD) pilot study - The RESOLVD pilot study investigators. Circulation 100 , 1056-1064.

4. Klahr S, Morrissey J. (2002) Comparative effects of ACE inhibition and angiotensin II receptor blockade in the prevention of renal damage. Kidney Int 62, S23-S26.

5. Remuzzi G, Ruggenenti P, Perico N. (2002) Chronic renal diseases: Renopro-tective benefits of renin-angiotensin system inhibition. Ann Intern Med 136, 604-615

6. Weir MR. (2002) Progressive renal and cardiovascular disease: Optimal treatment strategies. Kidney Int 62, 1482-1492

7. Hilgers KF, Mann JF. (2002) ACE inhibitors versus AT1 receptor antagonists in patients with chronic renal disease. J Am Soc Nephrol 13, 1100-1108

8. Jafar TH, Schmid CH, Landa M, Giatras I, Toto R, Remuzzi G, Maschio G, Brenner BM, Kamper A, Zucchelli P, Becker G, Himmelmann A, Bannister K, Landais P, Shahinfar S, de Jong PE, de Zeeuw D, Lau J, Levey AS. (2001) Angiotensin-converting Enzyme Inhibitors and Progression of Nondiabetic Renal Disease: A MetaAnalysis of Patient - Level Data. Ann Intern Med 135, 73-87.

9. Lewis EJ, Hunsicker LG, Clarke WR, Berl T, Pohl MA, Lewis JB, Ritz E, Atkins RC, Rohde R, Raz I. (2001) Renoprotective effects of the angiotensin-receptor antagonist irbesartan in patients with nephropathy due to type 2 diabetes. N Engl J Med 345, 851-860.

10. Jacobsen P, Andersen S, Rossing K, Jensen BR, Parving HH (2003) Dual blockade of the renin-angiotensin system versus maximal recommended dose of ACE inhibition in diabetic nephropathy. Kidney Int 63, 1874-1880.

11. Ruggenenti P, Perna A, Gherardi G, Garini G, Zoccali C, Salvadori M, Scolari F, Schena FP, Remuzzi G. (1999) Renoprotective properties of ACE-inhibition in non-diabetic nephropathies with non-nephrotic proteinuria. Lancet 354, 359-364.

12. Maschio G, Alberti D, Janin G, Locatelli F, Mann JF, Motolese M, Ponticelli C, Ritz E, Zucchelli P. (1996) Effect of the angiotensinconverting-enzyme inhibitor benazepril on the progression of chronic renal insufficiency. N Engl J Med 334, 939-945.

13. Brenner BM, Cooper ME, de Zeeuw D, Keane WF, Mitch WE, Parving HH, Remuzzi G, Snapinn SM, Zhang Z, Shahinfar S.(2001) Effects of losartan on renal and cardiovascular outcomes in patients with type 2 diabetes and nephropathy. N Engl J Med 345, 861-869.

14. Viberti G, Wheeldon NM. (2002) Microalbuminuria reduction with valsartan in patients with type 2 diabetes mellitus: a blood pressure-independent effect. Circulation 106, 672-678.

15. Mogensen CE, Neldam S, Tikkanen I, Oren S, Viskoper R, Watts RW, Cooper ME. (2000) Randomised controlled trial of dual blockade of renin-angiotensin system in patients with hypertension, microalbuminuria, and non-insulin dependent diabetes: the candesartan and lisinopril microalbuminuria (CALM study). Brit Med J 321, 1440-1444.

16. Salinger J, Pumprla J, Vychodil R, Stejskal P, Opavský J, Novotný J, Bula J (1999) Microcomputer system for telemetric assessment of short term heart rate variability in time and frequency domain, type VariaCardio TF 4. Computers in cardiology, IEEE 26, 599-602.

17. Šlachta R, Stejskal P, Elfmark M, Salinger J, Kalina M, Rehová I. (2002) Age and spectral analysis of heart rate variability. Gymnica $32,13-18$.

18. Cupisti A, Rizza GM, D’Alessandro C, Morelli E, Barsotti G. (2003) Effect of telmisartan on the proteinuria and circadian blood pressure profile in chronic renal patients. Biomedicine and Pharmacotherapy 57, 169-172.

19. Tesař V. (2002) Vliv léčby inhibitory angiotensin konvertujícího enzymu a antagonisty angiotensinu na progresi chronických nefropatí. Aktuality v nefrologii $8,83-88$.

20. Akselrod S, Gordon D, Ubel FA, Shannon DC, Barger AC, Cohen RJ. (1981) Power spectrum analysis of heart rate fluctuation: a quantitative probe of beat to beat cardiovascular control. Science 213, 220-222.

21. Bonaduce D, Marciano F, Petretta M, Migaux ML, Morgano G, Bianchi V, Salemme L, Valva G, Condorelli M. (1994) Effect of converting enzyme inhibition of heart period variability in patients with acute myocardial infarction. Circulation 90, 108-113.

22. Taylor JA, Carr DL, Myers ChW, Eckberg DL. (1998) Mechanisms underlying very-low-frequency RR-interval oscillations in humans Circulation 98, 547-555

23. Heusser K, Vitkovsky J, Schmieder RE, Schobel HP. (2003) AT1 antagonism by eprosartan lowers heart rate variability and baroreflex gain. Autonomic Neuroscience-Basic \& Clinical. 107(1), $45-51$ 